\title{
Effect of Simple Phenolic Glycosides on the Elongation of Avena First Internodes
}

Phenolic compounds are considered to day as an individual group of plant growth regulators ${ }^{1}$. The mechanism of their action might be different ${ }^{2-4}$. Phenolic compounds and their derivatives, e.g. glycosides and glucose esters were considered in the past to be waste by-products of plant metabolism. Recently phenolics were found to inhibit of stimulate the oxidative degradation of IAA $^{5}$. Glycosides and glucose esters being the most important bound forms of phenolic compounds in vivo. The enzymes, glycosidases, are supported to be involved in the maintainance of free phenolics pool within the cells. We have reported ${ }^{6}$, that $\beta$-glycosidase and IAA-oxidase systems are linked through glycosides and their biochemically active aglycones. To demonstrate such a correlation also in vivo we have studied the effect of simple phenolic glycosides on the elongation of Avena coleoptile sections in absence of exogenous IAA.

Methods. The plant material was tested with arbutin and gein (eugenol- $\beta$-vicianoside; end concentrations $10^{-3}$ to $10^{-5} M$ ) in incubation medium according to HENDERSON and NirscH ${ }^{7}$. Incubation medium contained phosphate buffer $\mathrm{pH} 5.5,2 \%$ sucrose and $0.1 \%$ Tween 80 . In control experiments the mentioned solution with and without $1 \%$ glucose was used. The initial length of sections was $2 \mathrm{~mm}$. The growth of the sections was measured after $20 \mathrm{~h}$ of incubation at $25^{\circ} \mathrm{C}$ in the dark.

Results and discussion. The results (average of 4 sets of 60 sections each) are shown in the Table. The results were

The Effect of arbutine and gein on the oat coleoptile growth

\begin{tabular}{lll}
\hline $\begin{array}{l}\text { Concentration } \\
(M)\end{array}$ & & $\begin{array}{l}\text { Growth } \\
(\%)\end{array}$ \\
\hline Arbutine & $\mathbf{1 0}-\mathbf{3}$ & 109,7 \\
& $10^{-4}$ & 114.5 \\
\multirow{3}{*}{ Gein } & $10^{-5}$ & 106.9 \\
& $10^{-3}$ & 106.7 \\
Control with glucose $(1 \%)$ & $10^{-4}$ & 118.3 \\
& $10^{-5}$ & 107.2 \\
\hline
\end{tabular}

evaluated statistically using the $t$-test and were demonstrable at $P$ 0,01 level.

Both arbutin and gein in all concentration tested stimulated the elongation of Avena coleoptile sections. The glucose in control samples was without any effect which demonstrated that glucose set free from glucosides did not interfere with growth of plat metarial.

These results correspond to the effects of quinol and eugenol on the purified IAA-oxidase described previously ${ }^{6}$.

Based on our findings the relationship between IAAoxidase and $\beta$-glycosidase have been found not only in vitro, but also in vivo.

Zusammenfassung. Nachweis, dass phenolische Glykoside Arbutin und Gein das Wachstum der Avena-Koleoptilen-Schnitte positiv beeinflussen, was auf eine Beziehung dieser Glycoside $z \mathrm{u}$ wachstumregulierenden Mechanismen hinweist.

\section{PŠEnÁK and G. VIZÁrovÁ}

Department of Biochemistry and Microbiology, Faculty of Pharmacy, Comenius University, Kalinciakowa 8, Bratislava (Czechoslovakia), and Institute of Botany, Slovak Academy of Sciences, Department of Plant Physiology, Dübravská cesta 26, Bratislava (Czechoslovakia), 30 November 7971.

\section{Comparative Studies on the Action of the Optical Antipodes of the Hypolipidaemic Aryloxyalkanoic Acid, CH 13 437, on Liver Enzymes of the Rat}

2-Methyl-2-[p-(1, 2, 3, 4-tetrahydro-1-naphthyl) - phen oxy]-propionic acid ( $\mathrm{CH}$ 13437), a compound which belongs to the group of aryloxy-alkanoic acids, is a substance with a strong hypolipidaemic action 1,2 . In experiments with humans, it shows also a distinct lowering of the blood lipids $^{3-5}$. Biochemical investigations of the action on liver metabolism of the rat indicate an inhibition of lipogenesis as the cause of the hypolipidaemic action ${ }^{6-8}$.

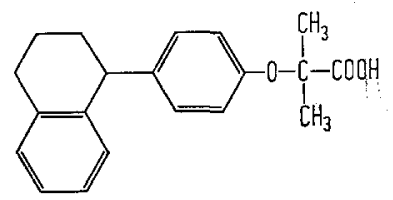

As shown by the Formula, compound $\mathrm{CH} 13437$ possesses an asymmetric carbon atom in the 1-position of the tetra-
${ }^{1}$ R. TURetskaya, V. Kefeli, M. KUtáček, K. Vacková, N. TschuMAKOVSKI and T. KRUPNIKOVA, Biologia Pl. 10, 205 (1968).

2 E. Libbert, S. Wichner, U. Schiewer, H. Risch and W. Kaiser, Planta 68,327 (1966).

${ }^{3}$ G. Stenlid and K. Saddik, Physiologia Pl. 15, 369 (1962).

${ }^{4} \mathrm{~J}$. W. Cornforth, Bl Milborrov, G. Ryback and P. E. Wareing, Nature, Lond. 205, 1269 (1965).

5 R. C. HARE, Bot. Rev. 30, 129 (1964).

6 M. PŠEnák, A. JindRA and P. Kovács, Biologia P1. 12, 241 (1970).

7 J. H. HeNDERSON and J. P. NitsCH, Nature Lond. 195, 780 (1962). hydronaphtalene ring. Consequently we were interested in comparing the action of the optical antipodes, and for this purpose we examined in rats those liver enzymes of the carbohydrate and lipid metabolism which in earlier

1 R. Hess and W. L. Bencze, Experientia 24, 418 (1968).

2 R. Hess, R. Mater and W. StäUbli, in Advances in Experimental Medicine and Biology (Eds. W. L. Holmes, L. A. CARLson and R. PAOletti, 1969), vol. 4, p. 483.

${ }^{3}$ M. M. Best and C. H. Duncan, J. Atheroscler. Res. 10, 103 (1969).

4 P. Oriente, M. Motolese, R. Cerqua and M. Mancini, Int. J. clin. Pharmac. 2, 348 (1969).

${ }^{5}$ G. HARTMAN and G. Forster, J. Atheroscler. Res. 10, 235 (1969).

${ }^{6}$ U. Schacht and E. Granzer, Biochem. Pharmac. 19, 2963 (1970).

7 M. E. Maragoudakis, Biochemistry 9, 413 (1970).

8 M. E. Maragoudakis and H. Hankin, J. biol. Chem. 246, 348 (1971). 